\title{
Temporal Partitioning by Animals Visiting Salt Licks
}

\author{
Jason Hon and Shozo Shibata
}

\begin{abstract}
Temporal partitioning of resources according to feeding period occurs in situation of food type specialization, such as for the use of salt licks by ecologically similar animal species. Camera traps placed at salt licks can be used to determine animal activity patterns. This study was carried in a logging concession area in central Sarawak, Malaysian Borneo. Sampling was carried from September 2010 to January 2011, and May to September 2011. Activity data at salt lick sites showed that sambar deer Rusa unicolor was mostly nocturnal, with high number of records occurring after dark from 20:00hrs onwards, peaking after midnight before slowly decreasing until early morning at 08:00hrs. Bornean yellow muntjac's Muntiacus antherodes activity was restricted to during the day, which peaked at 11:00 to 12:00hrs. There was no clear pattern observable in mousedeer Tragulus spp. and bearded pig Sus barbatus activity data. Significant differences between the proportion of daily activity were observed between Bornean yellow muntjac and bearded pig (Mann-Whitney-Wilcoxon test, $W=165.5, p=0.004$ ), followed by sambar deer $(W=195.5, p=0.053)$ and mousedeer $(W=213$, $p=0.074)$. Human presence and hunting pressure may affect the behaviour of some game species, such as the Bornean yellow muntjac which showed peak activity periods during the earlier part of the day, and over a much shorter time span in more human accessible salt lick sites.
\end{abstract}

Index Terms-Salt licks, Sarawak, temporal partitioning, visitation rate.

\section{INTRODUCTION}

Different types of animals may be active during different time of the day. In ecology, the principle on competitive exclusion indicates differences in realized niches existed so that ecologically similar species can coexist [1]. In a predator-prey relationship, spatial overlaps may be important in predicting encounter probabilities [2]. Studies have documented the use of salt licks by a wide range of species guild, such as carnivores, herbivores-frugivores, insectivores and omnivores and ungulates [3], [4]. A salt lick in general, refers to a mineral rich site which is frequently and actively visited by animal for the purpose of consuming minerals deposited there, through licking or geophagy [3]-[5].

Temporal partitioning of resources according to feeding

Manuscript received December 11, 2012; revised January 10, 2013. This work was supported in part by the Environmental Management Leader Program and Graduate School of Global Environmental Studies, Kyoto University, and Planted Forest in Equatorial Southeast Asia: Human-nature Interactions in High Biomass Society Project funded by Grant-in-Aid for Scientific Research(S), Japan Society for the Promotion of Science.

J. Hon is with the Graduate School of Global Environmental Studies, Kyoto University, Yoshida-Honmachi, Sakyo-ku, Kyoto, 606-8501, Japan (e-mail: jasonhonss@gmail.com).

S. Shibata is with the Laboratory of Landscape Ecology and Planning and the Graduate School of Global Environmental Studies, Kyoto University, Yoshida-Honmachi, Sakyo-ku, Kyoto, 606-8501, Japan (e-mail: sho@kais.kyoto-u.ac.jp). period occurs in situation of food type specialization [6], of which salt licks contain high levels of minerals required by animals but lacking in their diets [3]. The need to visit salt lick for nutrient uptake outweighs the risks of predation and also at the expense of time and energy used up for travelling [7]-[9].

We hypothesized animals of specific guild such as ungulates and carnivores, when visiting salt licks would demonstrate time partitioning and have certain peak periods in terms of visitation rate. This enable optimal use of the resource and to minimize overlaps with other species, especially between prey and predator. Camera traps have been used extensively to document activity patterns of wildlife [4], [10], [11].

\section{MATERIALS AND METHODS}

\section{A. Study Site}

The study was conducted inside a logging concession area called Anap Sustainable Development Unit (ASDU) in central Sarawak, a Malaysian state in the island of Borneo. ASDU is a landscape mosaic comprising of forest plantation, natural forest, agricultural land and human settlements. Here, three salt licks have been identified and are referred to as ApanSebedi ( $\left.\mathrm{N} 2.5937^{\circ} \mathrm{E} 112.8254^{\circ}\right)$, ApanMalat (N2.5292 ${ }^{\circ}$ E1 $\left.12.8543^{\circ}\right)$ and Apan_11 (N2.3861 ${ }^{\circ}$ E1 $\left.12.8468^{\circ}\right)$ as shown in Fig. 1. Apan is the local name for salt lick.

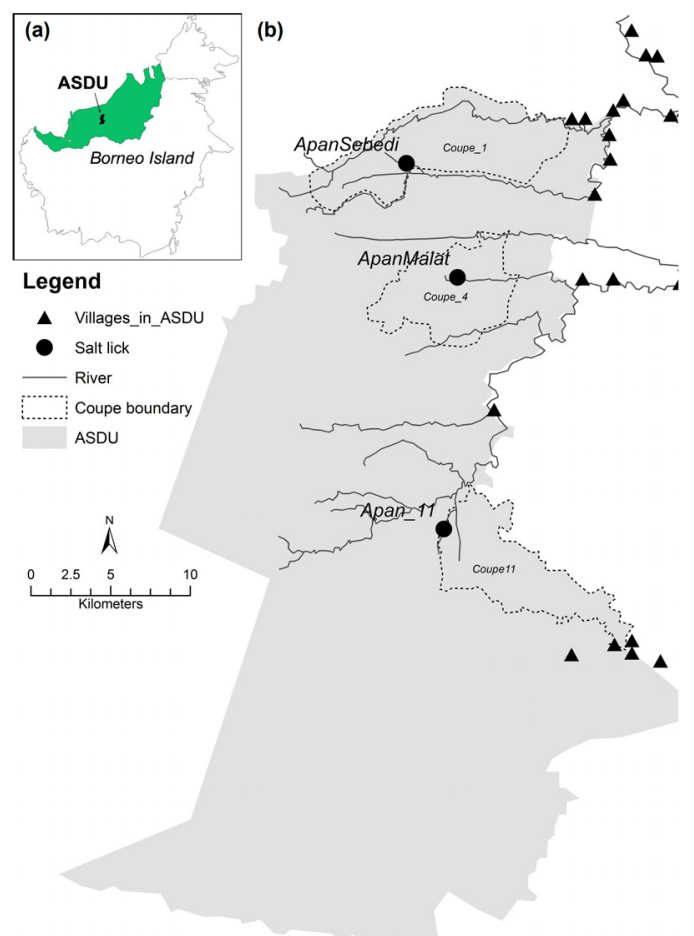

Fig. 1. Location of ASDU in Borneo; and locations of the salt lick study sites: ApanSebedi, ApanMalat, and Apan_11 (b). 


\section{B. Survey with Camera Traps}

We used a combination of Bushnell ${ }^{\circledR}$ TrophyCam $^{\mathrm{TM}}$ [12] and FieldNote [13] passive infra-red automatic trigger cameras, which we refer to as camera traps, to record species of animals visiting salt lick. At each salt lick, two units of camera traps were set up at a height of approximately $80 \mathrm{~cm}$ above ground, focusing onto the source of salt lick. The camera traps were set to record in video mode. Length of each recording was 30 seconds with one minute intervals in between recordings. Care was taken to ensure that the camera traps were placed in positions that did not physically obstruct animal's movements. We tested the camera traps by crawling in front, mimicking the movements of a passing animal. Where necessary, vegetations obstructing the field of view of the camera traps were minimally cleared to prevent the camera from being falsely triggered by movements caused by windblown vegetations. Camera traps remained continuously activated for 24-hour every day, and were visited between one to three months later to replace the batteries and memory cards. Samplings were carried out from September 2010 to January 2011, and May to September 2011. The total camera trapping effort amounted to 262 camera trap-days in Apan_11, 186 camera trap-days in ApanMalat, and 305 camera trap-days in ApanSebedi.

\section{Data Analysis}

The temporal niche of species of animals utilizing salt licks was determined by examining all records of videos captured by camera traps, which had information of time, which was recorded in hh:mm:ss format, and date. This information was collated and plotted on a time scale graph to determine the hour of the day that a certain species was most active and when visits to salt licks were made. Recording in video mode allowed us to view the subject matter in motion format, which subsequently led to better identification of animal species as compared to still images.

We refer to camera trap records as captures, which we subsequently classified into three time categories. Animals recorded between 19:01hrs to $05: 00 \mathrm{hrs}$ were classified as nocturnal; $07: 01 \mathrm{hrs}$ to $17: 00 \mathrm{hrs}$ were diurnal; and crepuscular periods were 17:01-19:01hrs and 05:01-07:00hrs. Animals with no clear patterns or peak activity were classifies as cathemeral. The categories were slightly modified based on the ones proposed by van Schaik \& Griffiths [14], whereby the cut-off time for crepuscular activity was slightly adjusted to create hourly intervals instead of half-hourly intervals for better tabulation of results The proportion of total daily activity occurring during each hour, $A$ was determined, by dividing the number of captures in an hour by the total number of captures for the 24-hr period [15]. The values of $A$ for respective animals were then compared using Mann-Whitney-Wilcoxon test for the null hypothesis that the populations of animals are identical between the two. All statistical analyses were conducted using $\mathrm{R}$ 2.15.0 [16]. We classified a capture as an independent record if more than 30 minutes had elapsed between records of the same species at the same location [17]. We calculated the encounter rate by first multiplying the number of captures by 100 and then divided the value by the camera trapping effort.

\section{RESUlTS}

\section{A. Activity Patterns}

Ungulates were the most frequently encountered species at salt licks, accounting for $63.5 \%$ of the total 400 captures of animals at all three salt lick sites. Sambar deer Rusa unicolor had the highest encounter rate among all species, with an average encounter rate of $12.5 \pm 5.84$ captures per camera trap-day. The encounter rate was also high at Apan_11 with 22.90 captures per camera trap-days and at ApanMalat with 13.64 captures per 100 camera trap-days. Pig-tailed macaque Macaca nemestrina was the second most encountered species, with an average encounter rate of $9.46 \pm 2.97$ captures per camera trap-days for all three salt licks combined. Other species in descending order of encounter rates were bearded pig Sus barbatus (7.82 \pm 2.23), mousedeer Tragulus spp. $(5.07 \pm 1.92)$, common porcupine Hystrix brachyura (2.65 \pm 1.34$)$, and Bornean yellow muntjac Muntiacus antherodes $(2.72 \pm 2.42)$. Identification of lesser mousedeer $T$. kanchil and greater mousedeer $T$. javanicus from camera trap records were difficult, so we treated all mousedeer as morphospecies.

The activity data at salt lick sites showed that sambar deer was mostly nocturnal, with high number of captures after dark from 20:00hrs onwards, peaking after midnight before slowly decreasing until early morning at 08:01hrs (Fig. 2). On the contrary, Bornean yellow muntjac's activity was restricted to during the day, starting from 06:00hrs, peaking at between 11:01 and 12:00hrs, with some activities after 17:01 hrs but not after 19:01 hrs. There was no clear pattern observable in mousedeer activity data, which showed peak activity between 18:01 hrs and 20:00hrs, and remained active throughout the night, before dispalying another peak activity period from $06: 01 \mathrm{hrs}$ to $07: 00 \mathrm{hrs}$. Although mousedder vaguely showed some nocturnal activities, we classified it as cathemeral. Bearded pig was cathemeral, and was active throughtout the day, and showed more intensed activity during the night, from 19:01 hrs onwards until 01:00hrs. It remained active throughout the early morning and day time. Primate species such as pig tailed macaque and long tailed macaque were mostly diurnal, with peak activity periods from 07:01hrs until 18:00 hrs for pig tailed macaque, and a narrower period of between 10:01hrs to $17: 00 \mathrm{hrs}$ for long tailed macaque. There were only four captures of long tailed macaque and we acknowledge that the data may not explain the activity pattern of this species well. Common porcupine showed a nocturnal activity pattern, with its activity restricted to the period between 18:01hrs and 05:00hrs. The other species with considerable number of captures was great argus Argusianus argus, which were active during the period betwen 07:01 hrs and 15:00hrs, of which we classified as diurnal.

There were significant differences of the proportion of daily activity between Bornean yellow muntjac and the other three ungulate species. The difference was more obvious between Bornean yellow muntjac and bearded pig $(\mathrm{W}=165.5$, $\mathrm{p}=0.004)$, followed by sambar deer $(\mathrm{W}=195.5, \mathrm{p}=0.053)$ and mousedeer $(\mathrm{W}=213, \mathrm{p}=0.074)$ (Table I). Bornean yellow muntjac was the only ungulate species that is largely diurnal in its activity pattern, while the others ungulate species were 
either nocturnal e.g. sambar deer and mousedeer, or showed more intense activity during the night e.g. bearded pig. In between the three salt lick sites, the peak activity period for Bornean yellow muntjac was much earlier at ApanMalat, which recorded peak activity period between 05:01 hrs and 10:00hrs, as compared to Apan_11 (between 10:01hrs and 15:00hrs) and ApanSebedi (between 12:01 hrs and 17:00hrs) (Fig. 3). No clear differences in daily activity patterns could be observed for sambar deer, mousedeer and bearded pig.

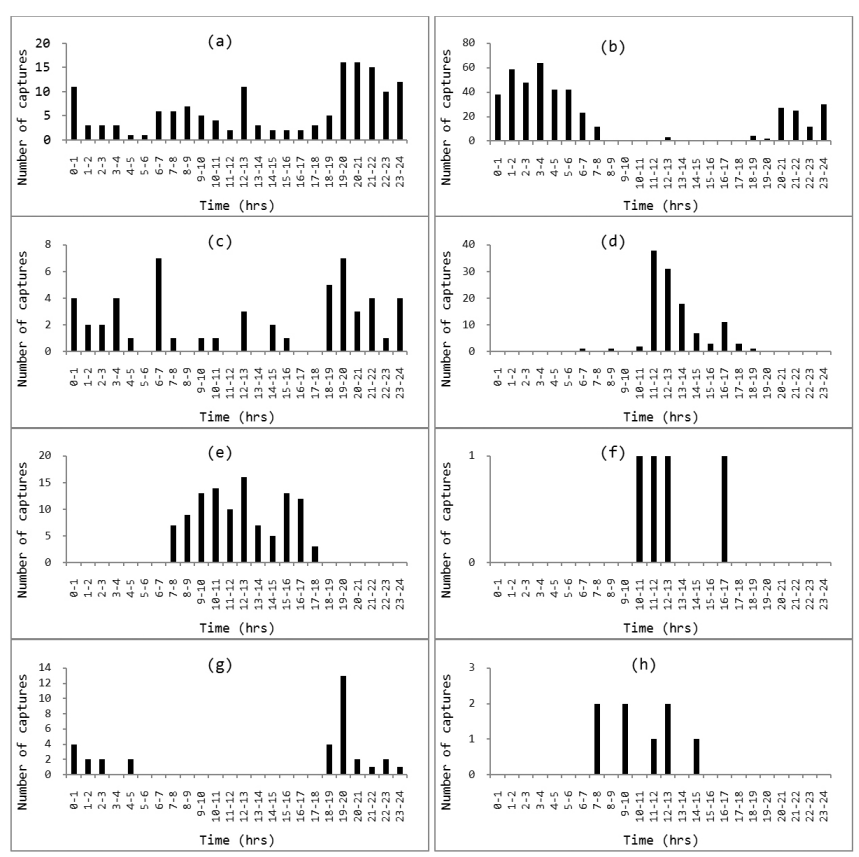

Fig. 2. Number of captures of bearded pig (a), sambar deer (b), mousedeer (c.) and Bornean yellow muntjac (d) long tailed macaque (e), pig tailed macaque (f), common porcupine (g), and great argus (h) at all salt lick sites combined. The starting time for every hourly interval on axis- $x$ is the first minute of the hour.

TABLE I: MANN-WHITNEY-WILCOXON TEST FOR THE PROPORTION OF TOTAL DAILY ACTIVITY AT SALT LICK SITES.

\begin{tabular}{lll}
\hline \hline $\begin{array}{l}\text { Animal pairs } \\
\text { comparison }\end{array}$ & $\begin{array}{l}\text { Daily activity pattern } \\
\text { relationship }(\mathrm{d}=\text { diurnal, } \\
\mathrm{n}=\text { nocturnal, ca }= \\
\text { cathemeral) }\end{array}$ & $\begin{array}{l}\text { Test result and } \mathrm{p} \text {-values } \\
\text { (significant values are } \\
\text { marked } * \text { for } \alpha=0.05 \text { and } \\
* * \text { for } \alpha=0.1)\end{array}$ \\
\hline $\begin{array}{l}\text { Sambar deer and } \\
\text { mousedeer }\end{array}$ & $\mathrm{n}-\mathrm{n}$ & $\mathrm{W}=288, \mathrm{p}=1$ \\
\hline $\begin{array}{l}\text { Sambar deer and } \\
\begin{array}{l}\text { Bornean yellow } \\
\text { muntjac }\end{array}\end{array}$ & $\mathrm{n}-\mathrm{d}$ & $\mathrm{W}=195.5, \mathrm{p}=0.053^{* *}$ \\
\hline $\begin{array}{l}\text { Sambar deer and } \\
\text { bearded pig }\end{array}$ & $\mathrm{n}-\mathrm{ca}$ & $\mathrm{W}=344, \mathrm{p}=0.25$ \\
\hline $\begin{array}{l}\text { Bornean yellow } \\
\text { muntjac and } \\
\text { mousedeer }\end{array}$ & $\mathrm{d}-\mathrm{n}$ & $\mathrm{W}=213, \mathrm{p}=0.074^{* *}$ \\
\hline $\begin{array}{l}\text { Bornean yellow } \\
\text { muntjac and } \\
\text { bearded pig }\end{array}$ & $\mathrm{d}-\mathrm{ca}$ & $\mathrm{W}=165.5, \mathrm{p}=0.004^{*}$ \\
\hline $\begin{array}{l}\text { Mousedeer and } \\
\text { bearded pig }\end{array}$ & $\mathrm{n}-\mathrm{ca}$ & $\mathrm{W}=261, \mathrm{p}=0.58$ \\
\hline \hline
\end{tabular}

\section{DISCUSSION}

Camera traps placed at salt licks can record animal activity patterns, as has been used by many other studies (e.g. [4], [14], [18]). Recently developed camera traps are capable to record in video formats and can operate continuously for up to 6-months, which enabled recordings of animal activities over a very long period.
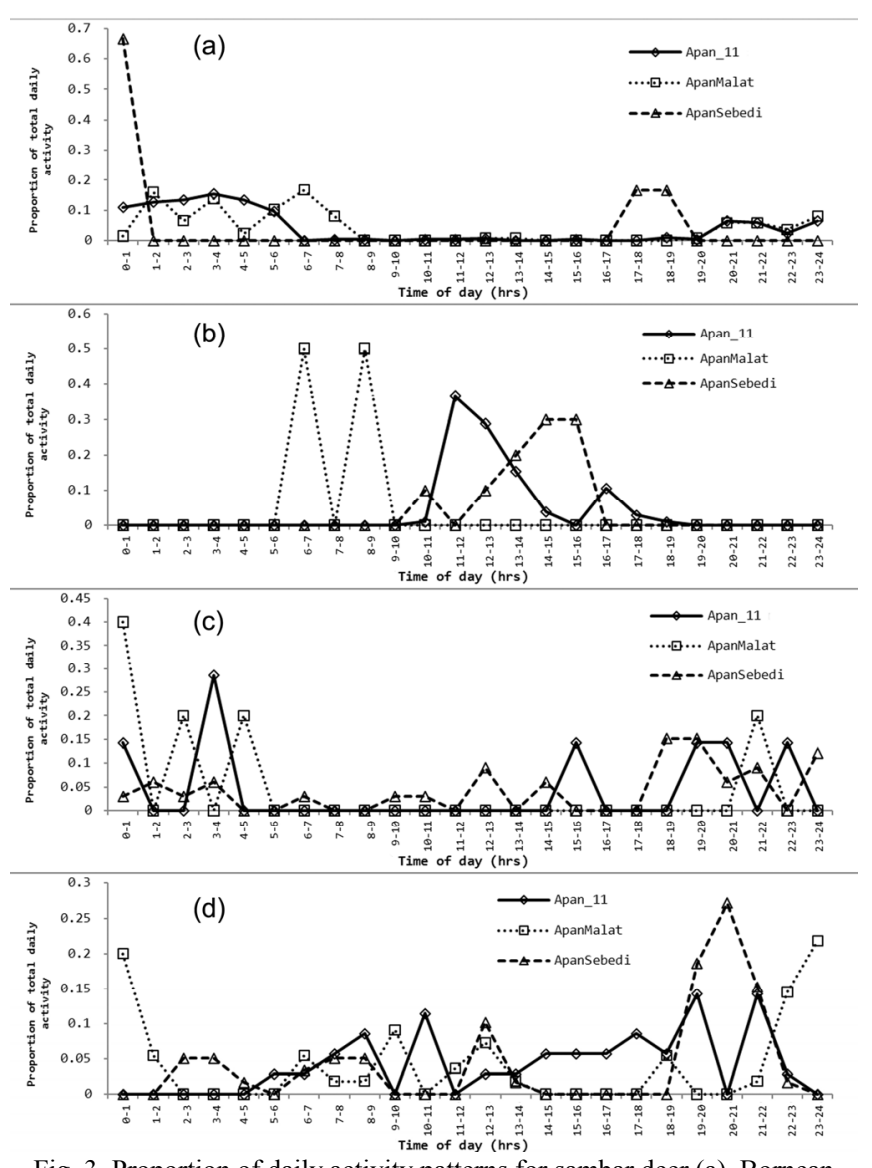

Fig. 3. Proportion of daily activity patterns for sambar deer (a), Bornean yellow muntjac (b), mousedeer (c), and bearded pig (d) at all salt lick sites combined The starting time for every hourly interval on axis-x is the first minute of the hour.

Ungulates have shown a high preference for salt lick, as they were the most frequently recorded species at all salt licks in this study. This shows that salt licks are important for plant eating species especially herbivores, presumably for their nutrient uptake. Within the guild of ungulates, data on activity patterns at salt licks demonstrated evidence of temporal partitioning. Bornean yellow muntjac showed an exclusively diurnal activity pattern, a strategy that is adopted to avoid overlapping with sambar deer, mousedeer and bearded pig. Because of this adaptation, it occupies a wider habitat niche, hence was also more widespread in the study area. This species was also one of the more commonly encountered species in other non salt lick sites in ASDU (unpublished data).

Primates are largely diurnal in behavior. Both long tailed and pig tailed macaques were recorded at salt licks during the day only. Pig tailed macaques were the more numerous species between the two, and showed a peak activity period in the mid-afternoon. The same observation was reported by Bernstein [19], who noted that pig tailed macaques also travelled to water sources. Pig tail macaques are largely aboreal and are found in the medium levels of the canopy. Occasionally, they come down to the ground and is the most encountered species of primates travelling on the ground [19]. In this study, pig tailed macaques may have visited the salt 
licks for their water source. We believe that other animals also use salt licks as source for water especially during the drier season when rainfall was lower. Fed by spring water, salt licks remained wet even during prolonged dry periods.

We acknowledge that camera traps are not the best tool to study aboreal species such as primates, as the static placement of the camera with fixed focus cannot detect what is beyond the range of the sensor. Our results on primates coming to the ground to visit salt licks may in the future, provide complementary information about the vertical movements of primates in the forest.

Some of the species are showed exclusively nocturnal behavior, such as the common porcupine which was only recorded at night. The nocturnal behavior of the common porcupine was also reported in other studies [20], [21]. On non-survey period, we never encountered this species while trekking in the forest during the day but frequently came across one or two individuals during the night. This showed that common porcupine is exclusively nocturnal.

The presence of carnivore species at salt licks, which prey on other animals, may affect the behavioural patterns of some species. Potential large carnivore species that prey on ungulates such as clouded leopard Neofelis diardi was not recorded at salt lick sites (unpublished data), indicating that predation from carnivores was not a strong factor on animal's behavior at salt lick sites. Other carnivore species recorded at salt licks were represented by small to medium sized species such as civets (Viverridae), and mongooses (Herpestidae), which are unlikely to prey upon the much larger ungulate species such as sambar deer, and muntjacs.

In fact, human presence and hunting pressure may affect the behaviour of some game species. This is based on the activity period of some species of ungulates that are hunted by the local people. Bornean yellow muntjac in more accessible salt lick site at ApanMalat showed peak activity periods during the earlier part of the day, and over a much shorter time span as compared to ApanSebedi and Apan_11 as indicated by the proportion of daily activity (Fig. 3). Sambar deer, Bornean yellow muntjac, mousedeer, and bearded pig were commonly hunted species in ASDU by the local communities, mostly for their local consumption.

Of all the three salt lick sites, ApanMalat and ApanSebedi are more accessible by the local communities. Because of the close proximity to the villages, hunting pressures at these salt lick areas were higher. This subsequently resulted in shorter peak activity period of animals, a strategy used in order to avoid being detected by hunters. Interviews with the local communities yielded information that the local people visit salt licks frequently to hunt. This information was substantiated by records from camera traps, which also 'captured' hunters at all three salt lick sites. Apart from hunters, hunting dogs, sometime travelling in packs of more than five animals were recorded at ApanMalat and ApanSebedi, but not at Apan_11. As hunters from ApanMalat and ApanSebedi could reach the respective salt licks more easily, hunting pressure increased which resulted in a more reclusive behavior of the commonly hunted species.

In another site in Indonesia where hunting and logging were absent, van Schaik \& Griffiths [14] reported that sambar deer, including many other ungulate species, were cathemeral. This data suggests that hunting, and possibly its inter-relatedness to logging [22] affects the activity patterns of wildlife. In all three salt lick sites, logging activities had ceased, a least one year prior to the survey was conducted. We had anticipated that logging would have caused the habitat to become less favourable and may have driven some species away from the site. In view of this, animals may not be frequently encountered or may not come out over prolonged period in such poorer conditions habitat. However, we discovered that species such as Bornean yellow muntjac and bearded pig spent quite substantial of their time at salt licks during the day in Apan_11, which was the most recently logged area of the three sites. It was also the least accessible site. Therefore, we believe that hunting is a major factor affecting animals' behavior in our study site.

The level of hunting is very low as compared to other sites in Sarawak that we are aware of, but management practices inside a production forest such as that inside a logging concession area, should take into account the need for conservation of wildlife. We put forth some of the recommendations for management. We propose that all access roads to salt licks are decommissioned after logging activity has ceased, and to ban any forms of hunting at all salt licks.

\section{ACKNOWLEDGMENT}

We would like to thank Wong Ing Yung and Zedtee Sdn. Bhd. for letting us conduct this study at ASDU and the logistical support provided during our fieldwork. We thank the discussions with H. Samejima, J. Tasan, W. Madun, and J. Jimmy in the field, who gave useful information on wildlife and hunting. The contribution of J.H.'s previous supervisor, Y. Morimoto, who has retired, is hereby acknowledged.

\section{REFERENCES}

[1] G. Hardin, "The competitive exclusion principle," Science, vol. 131, pp. 1292-1297, 1960.

[2] D. Griffiths, "Prey availability and the food of predators," Ecology, vol. 56, pp.1209-1214, 1975.

[3] H. Matsubayashi, P. Lagan, N. Majalap, J. Tangah, J. Abd. Sukor, and K. Kitayama, "Importance of natural licks for the mammals in Bornean inland tropical rain forests," Ecological Research, vol. 22, pp. 742-748, 2007.

[4] J. Ayotte, K. Parker, and M. Gilingham, "Use of natural licks by four species of ungulates in Northern British Columbia," Journal of Mammalogy vol. 89, no. 4, pp.1041-1050, 2008.

[5] O. Montenegro, "Natural licks as keystone resources for wildlife and people in Amazonia," PhD dissertation, University of Florida, 2004.

[6] T. Schoener, "The compression hypothesis and temporal resource partitioning," in Proceedings of the National Academy of Science, vol. 71 , pp. 4169-4172, 1974.

[7] C. Hui, "Geophagy and potential contaminant exposure for terrestrial vertebrates," Review of Environmental Contaminants and Toxicology vol. 183, pp. 115-134, 2004.

[8] D. Klein and H. Thing, "Geophagy at natural licks and mammal ecology: a review," Mammalia vol. 62, pp. 481-497, 1989.

[9] J. Ayotte, K. Parker, J. Arocena, and M. Gillingham, "Chemical composition of lick soils: functions of soil ingestion by four ungulate species," Journal of Mammalogy vol. 87, no. 5 , pp. 878-888, 2006.

[10] M. Tobler, S. Carrillo-Percastegui, and G. Powel, "Habitat use, activity patterns, and use of mineral licks by five species of ungulates in south-eastern Peru," Journal of Tropical Ecology vol. 25 , pp. 261-270, 2009 . 
[11] M. Weckel, W. Giuliano, and S. Silver, "Jaguar (Panthera onca) feeding ecology: distribution of predator and prey through time and space," Journal of Zoology vol. 270 , pp. 25-30, 2006.

[12] Bushnell. (December 2012). Bushnell Trophy Cam. [Online]. Available:

http://www.bushnell.com/hunting/trail-cameras/trophy-cam/trophy-ca $\mathrm{m}$.

[13] Marif. (December 2012). Marif FieldNote sensor camera. [Online]. Available: http://www.marif.co.jp/

[14] C. P. van Schaik and M. Griffiths, "Activity periods of Indonesian rain forest mammals," Biotropica, vol. 28, pp. 105-112, 1996.

[15] M. Hayward and R.Slotow, "Temporal partitioning of activity in large African carnivores: test of multiple hypotheses," South African Journal of Wildlife Research, vol. 39, no. 2, pp. 109-125, 2009.

[16] R Development Core Team, "R: a language and environment for statistical computing," R Foundation for Statistical Computing, Vienna, Austria, 2009.

[17] H. Samejima, R. Ong, P. Lagan, and K. Kitayama, "Camera-trapping rates of mammals and birds in a Bornean tropical rainforest unde sustainable forest management," Forest Ecology and Management vol 270 , pp. 248-256, 2012.

[18] D. Lizcano, and J. Cavelier, "Daily and seasonal activity of the mountain tapir (Tapirus pinchaque) in the Central Andes of Colombia," Journal of Zoology London, vol. 252, pp.429-435, 2000.

[19] I. Bernstein, "A field study of the pigtail monkey (Macaca nemestrina)," Primates, vol. 8, pp. 217-228, 1967.
[20] W. Novarino, "Population monitoring and study of daily activities of Malayan tapir (Tapirus indicus)," Rufford Small Grant \& Whitley Laing Foundation, 2005

[21] B. Giman, R. Stuebing, N. Megum, W. McShea and C. Stewart, "A camera trapping inventory for mammals in a mixed use planted forest in Sarawak," Raffles Bulletin of Zoology, vol. 55, no. 1, pp. 209-215, 2007

[22] E. Bennett and M. Gumal, The Cutting Edge: Conserving Wildlife in Logged Tropical Forests, Columbia University Press, 2001, ch. 16, pp. 359-374.

Jason Hon was born in Kuching, Sarawak, Malaysia on 19 April, 1975. He obtained BSc in Environmental Biology from the University of Science, Penang, Malaysia in 1995. He went to University of Aberdeen, UK and completed his MSc in Ecology in 2002.

He worked with the Sarawak Biodiversity Centre as a Zoologist from 1999 to 2001. Upon completing his MSc, he was attached to the Wildlife Conservation Society-Malaysia Programme and was the head of the Wildlife and Logging Unit.

Mr. Hon is a member of the Ecological Society of Japan. He was awarded the Chevening Scholarship to study for his MSc in the UK in 2001-2002. In 2010, he obtained the Japanese Monbukagakusho Scholarship to pursue his doctoral degree at Kyoto University. 